Article

\title{
The Depression and Adsorption Mechanism of Polyglutamic Acid on Chalcopyrite and Pyrrhotite Flotation Systems
}

\author{
Sultan Ahmed Khoso ${ }^{1,2}$, Zhiyong Gao ${ }^{1,2} \mathbb{C}^{\text {, Xiangsong Meng }}{ }^{1,2}$, Yuehua $\mathrm{Hu}^{1,2, *}$ and \\ Wei Sun ${ }^{1,2, *}$ \\ 1 School of Minerals Processing and Bioengineering, Central South University, Changsha 410083, China \\ 2 Key Laboratory of Hunan Province for Clean and Efficient Utilization of Strategic Calcium-Containing \\ Mineral Resources, Central South University, Changsha 410083, China \\ * Correspondence: huyuehuacsu@126.com (Y.H.); sunmenghu@csu.edu.cn (W.S.); Tel.: +86-0731-8830-482 \\ (Y.H.); +86-0731-8883-6873 (W.S.)
}

Received: 17 July 2019; Accepted: 22 August 2019; Published: 24 August 2019

\begin{abstract}
The rejection of pyrrhotite and pyrite has become a long-standing problem in the copper ore industry. This paper describes the first successful depression and adsorption mechanism of a novel and non-hazardous reagent, polyglutamic acid (PGA), on pyrrhotite in the selective flotation of chalcopyrite with xanthate as the collector, making use of various laboratory-scale measurement techniques. The addition of PGA inhibited the flotation of pyrrhotite much more strongly than that of the chalcopyrite in a wide $\mathrm{pH}$ range. The prior addition of PGA achieved an improved selective flotation of chalcopyrite from pyrrhotite at $\mathrm{pH} 8$, at which the grade and recovery of chalcopyrite in concentrate were over $80 \%$. Surface measurement techniques including XPS spectral, IR spectral, zeta potential, and reagent adsorption analyses indicated that the PGA interacted differently with the two minerals, and had much greater affinity towards pyrrhotite than chalcopyrite. The presence of PGA blocked the electrochemical activity of the collector on the pyrrhotite surface and thus depressed its flotation, whereas the adsorption of the collector and its oxidation to dixanthogen were more effective on the chalcopyrite surface, indicating a weaker interaction of PGA with chalcopyrite. Our results suggest that the application of PGA could replace the toxic inorganic depressants in flotation technology, and could significantly reduce the environmental impacts of processing.
\end{abstract}

Keywords: polyglutamic acid; PGA; depressant; pyrrhotite; chalcopyrite; flotation

\section{Introduction}

Copper, a nonferrous base metal, is required in every modern manufacturing industry. It is extracted mainly through the smelting processing of copper-bearing minerals. There are many minerals available for the production of copper, but chalcopyrite is the largest source from which copper is economically and efficiently extracted [1]. Gangue minerals containing iron as a dominant metal are part of a great majority of copper ore deposits [2]. Of these, pyrrhotite $\left(\mathrm{Fe}_{1-\mathrm{xS}}\right)$ and pyrite $\left(\mathrm{FeS}_{2}\right)$ are the two most common iron sulfide minerals. Pyrrhotite occurs either in hexagonal or monoclinic form. Monoclinic pyrrhotite is a strong ferromagnetic and is richer in sulfur, while the hexagonal form has no magnetic properties and is poorer in sulfur content [3]. Since the pyrrhotite contains relatively more iron (approximately $60 \% \mathrm{Fe}$ ) than pyrite (approximately $47 \% \mathrm{Fe}$ ), the misreporting of pyrrhotite in concentrates dilutes the grade of the metal $[3,4]$. Moreover, the presence of pyrrhotite increases the sulfur content in copper concentrates, which not only causes the corrosion of equipment but also pollutes the environment through $\mathrm{SO}_{2}$ emissions during the metallurgical processing $[5,6]$. 
Hence, the rejection of pyrrhotite from base metal sulfide ores in the initial stage of processing has various economic and environmental advantages. However, the removal of pyrrhotite in the presence of xanthate has been a long-standing problem in the copper ore industry.

Froth flotation is practically used for the separation of copper-bearing minerals from either pyrite or pyrrhotite gangues [7,8]. Its separation is based mainly on the difference in the physico-chemical characteristics of valuables and gangue minerals present in the ore body $[9,10]$. Well-known flotation reagents including collectors, depressants, frothers, and modifiers are commonly used to modify the hydrophobic/hydrophilic characteristics of mineral particles present in the mineral suspensions [11]. Many research studies have been carried out on the flotation of pyrrhotite over the past few decades, but different researchers have drawn different conclusions. In the literature, it is widely acknowledged that the crystal structure, chemical composition, and physical properties of pyrrhotite determine its floatability [12]. During flotation, the pyrrhotite is commonly rejected to the tailings as a waste product, and hence in massive sulfide ores treatment, the process often aims to depress the pyrrhotite flotation $[6,13,14]$. The pyrrhotite responds well to xanthate, the strong and most widely used thiol collector in base metal sulfide flotation $[15,16]$, and floats easily with the valuable minerals. Therefore, the mineral industry mostly needs a depressant for pyrrhotite in the flotation of copper minerals with xanthate as the collector.

There are many inorganic reagents available that have been applied for the depression of pyrrhotite flotation. Of these, high-pH reagents such as lime $(\mathrm{CaO})$, sodium hydroxide $(\mathrm{NaOH})$, and sodium carbonate $\left(\mathrm{Na}_{2} \mathrm{CO}_{3}\right)$ are widely used depressants for pyrrhotite in the conventional flotation circuits of the copper ore industry $[17,18]$. However, the depression of pyrrhotite by lime is comparatively more effective than by sodium hydroxide and sodium carbonate. In the presence of $\mathrm{CaO}$ in high-pH solutions, hydrophilic species like $\mathrm{Fe}(\mathrm{OH})_{3}, \mathrm{FeSO}_{4}$, and $\mathrm{CaSO}_{4}$ are formed on the pyrrhotite surface, which inhibits the adsorption of xanthate ions and thus depresses the flotation of pyrrhotite. The depression of pyrrhotite through lime usually requires larger doses of lime, which not only increases the operating cost but also reduces the plant performance if gypsum precipitation occurs. Moreover, in high-pH solutions, the electrochemical interaction of metal ions such as $\mathrm{Cu}^{2+}$ and $\mathrm{Pb}^{2+}$ may occur on the pyrrhotite surface during the grinding and flotation conditioning processes, which can activate the pyrrhotite flotation and diminish the selective depression, even in the presence of lime $[3,19,20]$. In addition to $\mathrm{pH}$ reagents, other highly toxic chemicals including potassium dichromates, sulfites, sulfur dioxides, and cyanides have also been applied for the inhibition of pyrrhotite flotation [14,16,21]. These depressant reagents have shown to be more effective in rejecting pyrrhotite; however, their applications are limited by environmental or economic concerns [22,23]. Therefore, the copper industry is constantly looking for a more suitable depressant of pyrrhotite in $\mathrm{Cu}-\mathrm{Fe}$ flotation separation.

Owing to their characteristics of renewability, biodegradability, abundant availability, environmental friendliness, and low cost, bio-based depressants have gained increasing industrial interest in recent years. The most common organic depressants for pyrrhotite flotation include mercapto organic compound (DMPS) [24], guar gum [25], diethylenetriamine [26], sodium metabisulfite and triethylenetetramine [27]. Microorganism bacteria, such as Leptospirillum ferriphilum and Acidithiobacillus caldus [28], have also been used to modify the surface properties of pyrrhotite, as an alternative to depress the pyrrhotite flotation. Some of these have shown favorable results in the rejection of pyrrhotite when used in laboratory-scale flotation experiments. Generally, the depression mechanism of organic polymers is either to desorb the collector or activator from the mineral surface, prevent the collector adsorption, or make the mineral surface more hydrophilic $[29,30]$. The hydrophilic functional groups in the molecular structure of organic polymers enhance the hydrophilic character of the mineral surface, facilitating the depression of mineral particles through the reduced possibility of bubble-particle attachment [31,32]. One limitation to the use of organic reagents as depressants is their poor selectivity; high doses of organic depressants may cause the depression of all sulfide minerals present in the flotation slurry. However, the main advantages of organic over inorganic depressants are that the biopolymers have much greater flexibility and potential to be modified physically or 
chemically, which can effectively improve their selectivity as well as depression performance. Hence, there is still significant scope for the development of bio-based reagents to produce specifically selective depressants to function effectively for a specific mineral or application.

The present paper therefore describes the first successful depression and adsorption mechanism of a novel and environmentally friendly depressant reagent, polyglutamic acid (PGA), on pyrrhotite in the selective flotation of chalcopyrite with xanthate as the collector, making use of single and binary mineral selective flotation experiments, X-ray photoelectron spectroscopy (XPS), infrared spectroscopy (IR), zeta potential measurements, and reagent adsorption analysis techniques. Polyglutamic acid or poly- $\gamma$-glutamic acid is chemically composed of D-and L-glutamic acid connected through amide linkages between $\gamma$-carboxylic acid and $\alpha$-amino groups [33]. It is a naturally occurring anionic polymer, and its charge varies depending on solution $\mathrm{pH}$. It has many outstanding properties, such as non-toxicity, renewability, water solubility, and biodegradability. Due to its biodegradability and non-toxicity to humans and the environment, the optimal usage of polyglutamic acid could extensively reduce the environmental impacts of processing. To the best of our knowledge, there is no reported work on the application of PGA as a flotation depressant of pyrrhotite in mineral processing.

\section{Methodology}

\subsection{Samples and Reagents}

The mineral samples of chalcopyrite and pyrrhotite used in this investigation were provided by Yunfu, Guangdong Province, China. The purity of samples was measured by X-ray diffraction analysis, as shown in Figure 1. For single and binary mineral selective flotation experiments, particles with $38-74 \mu \mathrm{m}$ size were produced via crushing, grinding, and sieving. The particles with size $<2 \mu \mathrm{m}$ were produced for XPS spectral measurements, IR spectral measurements, zeta potential measurements, and reagent adsorption analysis. After the sample preparation procedures, all of the samples were placed in sealed glass bottles to protect them from oxidation.
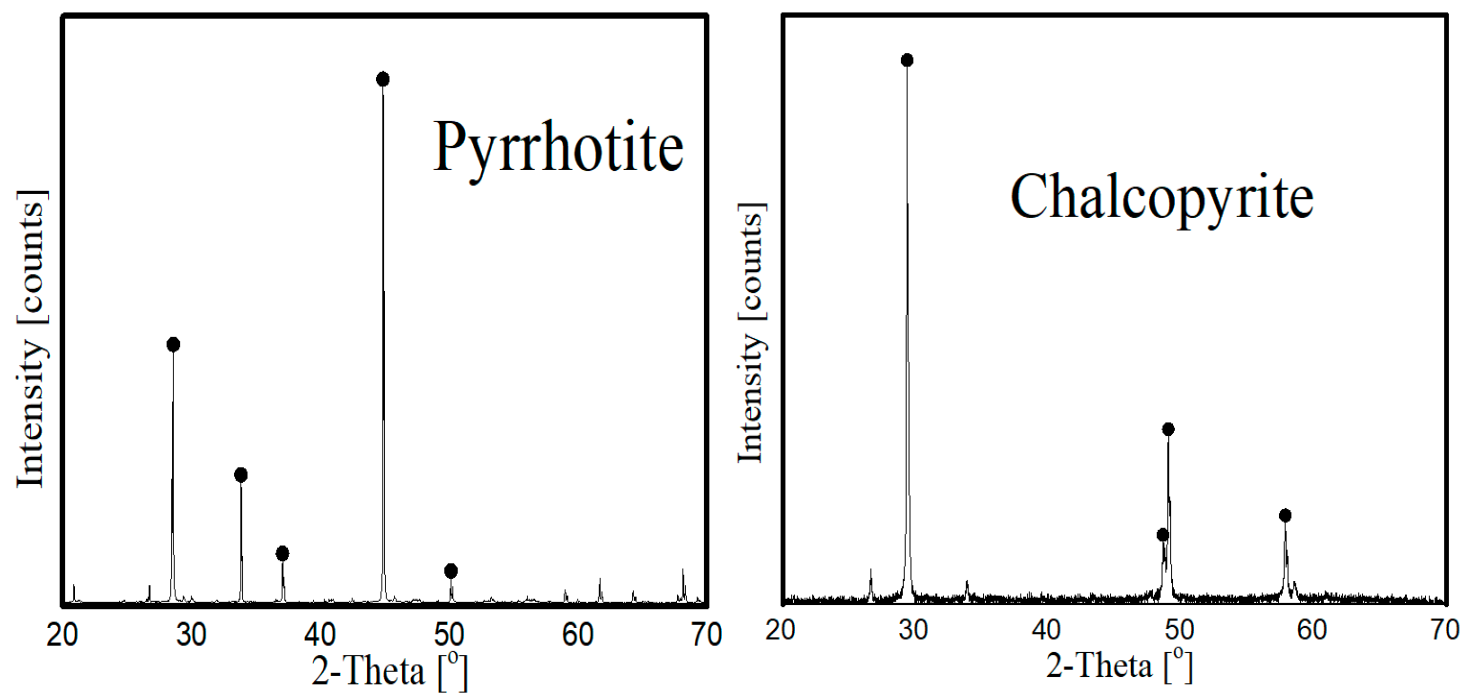

Figure 1. X-ray diffraction analysis of pyrrhotite and chalcopyrite.

Polyglutamic acid (PGA, analytical-grade reagent with $92 \%$ purity and relative molecular weight of 700,000) from Shanghai Macklin Biochemical Co., Ltd., China was used as the main depressant reagent in this study. Figure 2 shows the molecular structure and IR spectrum of PGA, and Table 1 presents the characteristic infrared peaks of the major functional groups in PGA. Sodium isobutyl xanthate (SBX), an industrial-grade collector with 95\% purity, was received from Chemical Factory of Zhuzhou, China. Analytical-grade terpineol was employed as the frothing agent, and sodium 
hydroxide and nitric acid were used as the $\mathrm{pH}$ modifiers. Deionized water (resistivity of $18.2 \mathrm{M} \Omega \cdot \mathrm{cm}$ ) was used in the experiments.

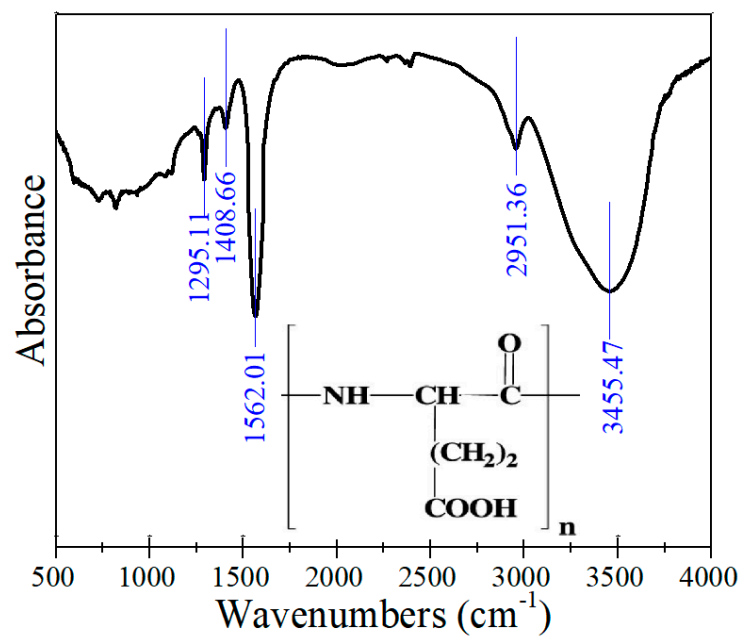

Figure 2. Chemical structure and IR results of polyglutamic acid.

Table 1. The main functional groups in polyglutamic acid.

\begin{tabular}{cc}
\hline Wavenumber $\left(\mathbf{c m}^{-\mathbf{1}}\right)$ & Assignment \\
\hline 1295.11 & $\mathrm{C}-\mathrm{N}$ stretching \\
1408.66 & $\mathrm{CO}_{2}^{-}$symmetric stretching \\
1562.01 & $\mathrm{CO}_{2}{ }^{-}$asymmetric stretching \\
2951.36 & $\mathrm{C}-\mathrm{H}$ stretching \\
3455.47 & $\mathrm{~N}-\mathrm{H}$ stretching \\
\hline
\end{tabular}

\subsection{Procedure of Flotation Experiments}

The depressive performance of PGA on pyrrhotite and chalcopyrite was evaluated via single and binary mineral selective flotation experiments using a $40 \mathrm{~mL}$ flotation cell and $1650 \mathrm{r} / \mathrm{min}$ impeller speed. All of the experiments were performed in an XFG series single flotation cell machine (Jilin Exploring Machinery Plant, Jilin, China) at room temperature $\left(25 \pm 1{ }^{\circ} \mathrm{C}\right)$. In each of the experiments, the pulp was prepared by mixing $2.0 \mathrm{~g}$ of the desired mineral with $35 \mathrm{~mL}$ of DI water into a $40 \mathrm{~mL}$ plexiglass cell. Following the $\mathrm{pH}$ adjustment with sodium hydroxide or nitric acid with a stirring time of $2 \mathrm{~min}$, the desired reagent was added and conditioned for $3 \mathrm{~min}$ each. Finally, the frother was added to mineral suspension with a $1 \mathrm{~min}$ conditioning time, and the concentrates and tails were collected for $5 \mathrm{~min}$, oven-dried at about $60^{\circ} \mathrm{C}$, and weighed for the recovery calculations. The adopted flotation procedure is illustrated in Figure 3. The procedure was repeated three times, and the average recovery was reported as the final value. Moreover, under same experimental situations, the standard deviation, which is represented by an error bar, was also calculated using the mean of three measurements. In binary mineral selective flotation experiments, the flotation experimental procedure was the same as shown in Figure 3. However, the flotation feed for binary mineral flotation was prepared by mixing the chalcopyrite and pyrrhotite in a 1:1 ratio, and the recovery and grade of the minerals were calculated based on solid mass distribution between the concentrates and tailings and their chemical composition. 


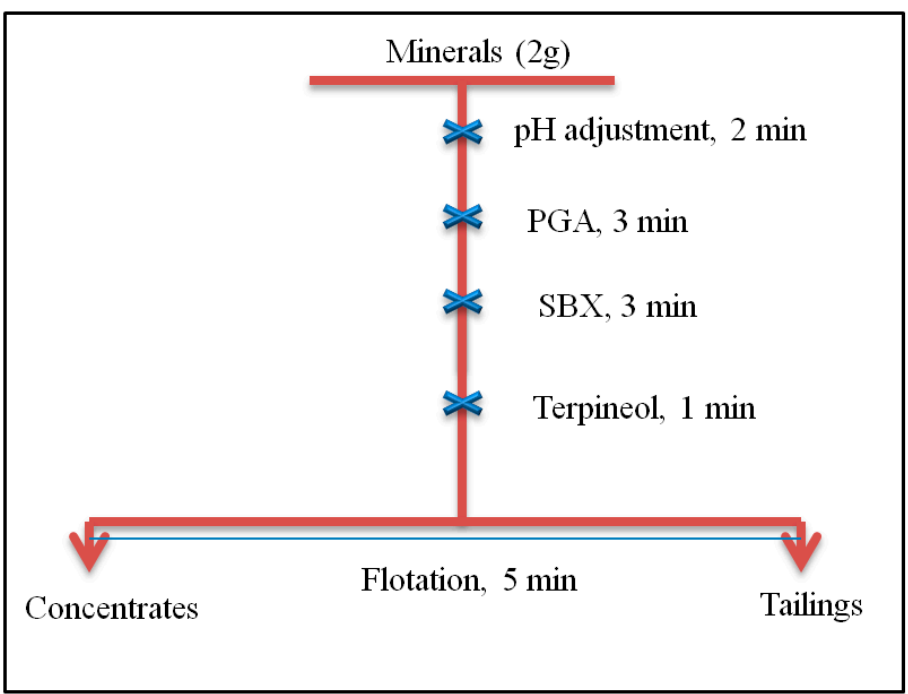

Figure 3. Adopted procedure for single and binary mineral selective flotation experiments.

\subsection{Zeta Potential of Minerals}

Zeta potential measurements were carried out in a ZETASIZER spectrometer (Nano-Zs90 series, Malvern Instruments, Worcestershire, UK) at room temperature $\left(25 \pm 1^{\circ} \mathrm{C}\right)$. In each of the measurements, tests were performed by mixing $0.020 \mathrm{~g}$ of the desired mineral particles of $<2 \mu \mathrm{m}$ size into a $1 \times 10^{-3} \mathrm{~mol} / \mathrm{L}$ $\mathrm{KCl}$ solution $(40 \mathrm{~mL})$ as the background electrolyte solution. Following the $\mathrm{pH}$ adjustment with sodium hydroxide or nitric acid with a stirring time of $2 \mathrm{~min}$, the desired reagent was added and conditioned for $10 \mathrm{~min}$ each. The addition order of the reagent(s) was the same as illustrated in Figure 3. After 5 min settling of the coarser particles, the $\mathrm{pH}$ of the solution was noted and the fine particles in the form of supernatant were transmitted to a cell for measurements. Three measurements were performed for each sample, and the average was calculated as the final value.

\subsection{Reagent Adsorption Measurements}

Using the solution depletion technique, the adsorbed amount of PGA on the surface of pyrrhotite and chalcopyrite was calculated at different PGA concentrations. All of the measurements were performed at room temperature $\left(25 \pm 1^{\circ} \mathrm{C}\right)$. In each of the measurements, the suspension was prepared by mixing $2.0 \mathrm{~g}$ of the desired mineral with $35 \mathrm{~mL}$ of DI water into a $40 \mathrm{~mL}$ plexiglass cell. Following the $\mathrm{pH}$ adjustment with sodium hydroxide or nitric acid with a stirring time of $2 \mathrm{~min}$, the desired dose of PGA was added to the mineral suspension and conditioned for $3 \mathrm{~min}$. After the conditioning time, each mineral solution was centrifuged at 10,000 rpm for $30 \mathrm{~min}$ in order to settle the solid particles, and the PGA residual concentration in the solutions was determined. A total organic carbon analyzer (TOC-LCPH, Shimadzu, Kyoto, Japan) was used for the determination of total organic carbon. The adsorbed amount of reagent was calculated using the following Equation (1):

$$
\Gamma=\frac{V}{1000 m}\left(C_{o}-C\right)
$$

where $\Gamma$ represents the adsorbed amount of reagent $(\mathrm{mg} / \mathrm{g}) ; V$ is the total volume of the solution $(\mathrm{L}) ; C_{o}$ and $C$ are the PGA concentrations in initial solution and supernatant, respectively, and $m$ represents the mass of the mineral sample $(\mathrm{g})$.

\subsection{Infrared Spectroscopy Analysis}

A Bruker Alpha FTIR spectrometer (Nicolet 6700, Thermo Scientific, Waltham, MA, USA) was used to collect the infrared spectra of mineral particles before and after the reaction with reagents. The samples were prepared by mixing $2.0 \mathrm{~g}$ of the desired mineral with $35 \mathrm{~mL}$ of DI water into a $40 \mathrm{~mL}$ 
plexiglass cell. Following the $\mathrm{pH}$ adjustment with sodium hydroxide or nitric acid with a stirring time of $2 \mathrm{~min}$, the desired reagent was added and conditioned for $20 \mathrm{~min}$ each. The addition order of the reagent(s) was the same as illustrated in Figure 3. After the treatment with reagent(s), mineral particles were rinsed with deionized water, filtered, and dried in a vacuum desiccator prior to the infrared spectroscopy measurements. In order to acquire the infrared spectra, about $1 \%$ of each mineral (mass fraction) was mixed with a spectroscopic-grade $\mathrm{KBr}$. All of the measurements were performed at room temperature $\left(25 \pm 1^{\circ} \mathrm{C}\right)$.

\subsection{X-ray Photoelectron Spectroscopy Analysis}

Using an ESCALAB 250Xi spectrometer (Thermo Fisher-VG Scientific, Waltham, MA, USA), the $\mathrm{X}$-ray photoelectron spectra of mineral particles before and after the reaction with reagents were collected with $\mathrm{Al} \mathrm{K} \alpha$ as the sputtering source at $12 \mathrm{kV}$ and $6 \mathrm{~mA}$. The pressure in the analyzer chamber was fixed at $1.0 \times 10^{-12} \mathrm{~Pa}$, and the binding energies of $\mathrm{C}(1 \mathrm{~s})$ were fixed at $284.8 \mathrm{eV}$. Thermo Scientific Avantage software was used for curve fitting and quantification of the spectra. The samples were prepared by mixing $2.0 \mathrm{~g}$ of the desired mineral with $35 \mathrm{~mL}$ of DI water into a $40 \mathrm{~mL}$ plexiglass cell. Following the $\mathrm{pH}$ adjustment with sodium hydroxide or nitric acid with a stirring time of $2 \mathrm{~min}$, the desired reagent was added and conditioned for $20 \mathrm{~min}$ each. The addition order of the reagent(s) was the same as illustrated in Figure 3. After the treatment with reagent(s), mineral particles were rinsed with deionized water, filtered, and dried in a vacuum desiccator prior to XPS measurements. All of the measurements were performed at room temperature $\left(25 \pm 1^{\circ} \mathrm{C}\right)$.

\section{Results and Discussion}

\subsection{Single Mineral Flotation}

The flotation performance of minerals with PGA as the depressant and SBX as the collector was first investigated through single-mineral flotation tests. As shown in Figure 4, in the absence of PGA, pyrrhotite and chalcopyrite exhibited excellent flotation with SBX, and their recoveries were more than $80 \%$ in a wide $\mathrm{pH}$ range of $2-11$. The improved flotation of chalcopyrite and pyrrhotite in this $\mathrm{pH}$ range was because of the adsorption of xanthate and its oxidation to stable dixanthogen on the mineral surfaces. Meanwhile, the decrease in flotation recovery at $\mathrm{pH}>11$ indicates that the oxidation of xanthate to dixanthogen was not thermodynamically stable in highly alkaline solutions, and thus was not adsorbed onto the mineral surfaces [34]. From these results it is clearly shown that the selective separation between the chalcopyrite and pyrrhotite was impossible without adding any depressant.

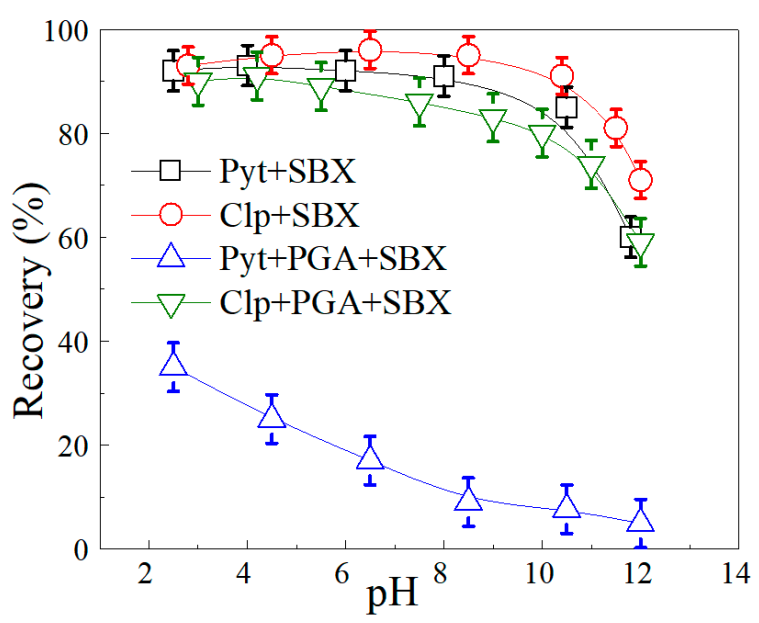

Figure 4. Flotation results of pyrrhotite (Pyt) and chalcopyrite (Clp) at $40 \mathrm{mg} / \mathrm{L}$ polyglutamic acid (PGA) and $20 \mathrm{mg} / \mathrm{L}$ sodium isobutyl xanthate (SBX). 
In the presence of PGA (added before SBX), the flotation recoveries of both minerals were decreased simultaneously, indicating that the PGA had a depressive effect on the mineral flotation. Figure 4 indicates that the addition of PGA depressed the two minerals differently; flotation of pyrrhotite was inhibited more strongly than that of the chalcopyrite in the whole tested $\mathrm{pH}$ range of 2-12, indicating that PGA could be a better depressant of pyrrhotite than chalcopyrite. The prior addition of PGA depressed the flotation recovery of pyrrhotite to about $10 \%$ from $85 \%$ in a $\mathrm{pH}$ range of $7-11$, whereas the recovery of chalcopyrite remained more than $80 \%$ under the same experimental conditions. These preliminary flotation results indicate that a selective separation window between the chalcopyrite and pyrrhotite exists with PGA as the depressant.

As shown in Figure 4, in the presence of PGA, the strongest depression of pyrrhotite and the largest difference between the recoveries of pyrrhotite and chalcopyrite occurred at $\mathrm{pH}>7$. To investigate the effect of different concentrations of PGA on the flotation behavior of these minerals, single-mineral flotation tests were extended further by fixing the $\mathrm{pH}$ at 8 . Figure 5 shows that by increasing the doses of PGA from 10 to $110 \mathrm{mg} / \mathrm{L}$, the flotation recoveries of pyrrhotite and chalcopyrite were also decreased; however, the decreasing effect on pyrrhotite was much stronger than that of the chalcopyrite. As shown, an important recovery difference was again obtained at the lower concentration of PGA (i.e., 10-60 mg/L), indicating that PGA has a great potential to depress the flotation of pyrrhotite in the selective flotation of chalcopyrite with xanthate as the collector. These results therefore suggest that PGA could be an alternative inhibitor for iron sulfide gangues in the conventional flotation procedures of the copper ore industry.

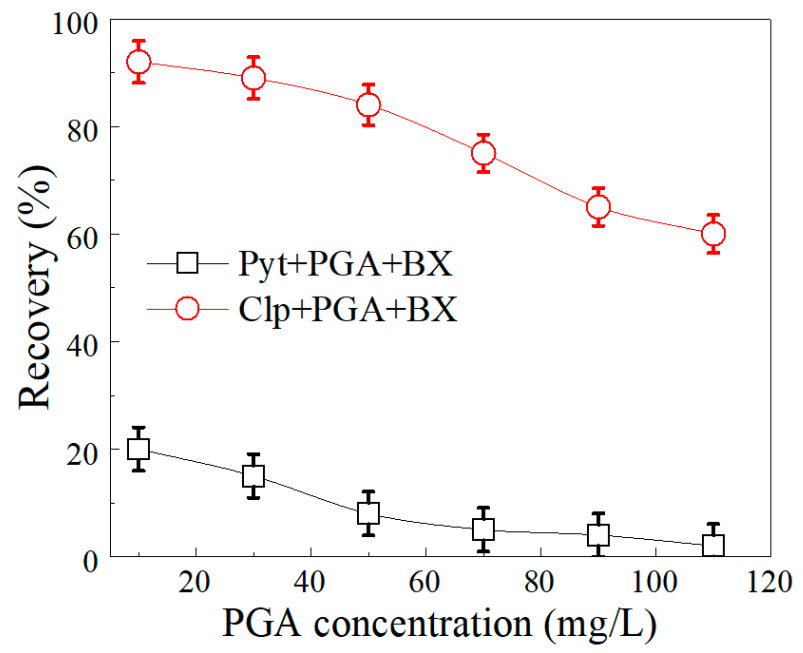

Figure 5. Flotation results of pyrrhotite (Pyt) and chalcopyrite (Clp) at different PGA concentrations, $20 \mathrm{mg} / \mathrm{L} \mathrm{SBX}$, and $\mathrm{pH} 8$.

\subsection{Selective Flotation}

Flotation experiments on the individual minerals clearly showed that the prior addition of PGA depressed the flotation of pyrrhotite more strongly than that of the chalcopyrite. In addition to single-mineral flotation, the selective flotation experiment on manually mixed minerals is the best laboratory measurement to reveal the selectivity of any new reagent as a collector or depressant. In this regard, binary mineral selective flotation experiments were further conducted by using the optimized experimental parameters: $50 \mathrm{mg} / \mathrm{L} \mathrm{PGA}, 20 \mathrm{mg} / \mathrm{L} \mathrm{SBX}$, and $\mathrm{pH}$ 8. Flotation feed for selective flotation experiments was prepared by blending the chalcopyrite and pyrrhotite minerals in a 1:1 ratio. Table 2 provides the selective flotation results.

A significant improvement in the grade of concentrate compared with feed before flotation revealed that an improved selective separation of chalcopyrite from pyrrhotite occurred by adding PGA as the depressant. The addition of PGA produced a flotation concentrate with a chalcopyrite 
grade of more than $80 \%$, with an improved recovery of more than $85 \%$. Whereas, under the same experimental conditions the grade and recovery of pyrrhotite remained less than $20 \%$. These results indicate that in the mineral suspension where both chalcopyrite and pyrrhotite were present together, the PGA selectively adsorbed onto the surface of pyrrhotite, depressed its flotation, and allowed the chalcopyrite to float from the suspension.

Table 2. Selective flotation results of the binary mixed chalcopyrite and pyrrhotite at $50 \mathrm{mg} / \mathrm{L} \mathrm{PGA}$, $20 \mathrm{mg} / \mathrm{L} \mathrm{SBX}$, and $\mathrm{pH} 8$.

\begin{tabular}{cccccc}
\hline \multirow{2}{*}{ Products } & Yield & \multicolumn{2}{c}{ Recovery (\%) } & \multicolumn{2}{c}{ Grade (\%) } \\
\cline { 2 - 6 } & $\mathbf{( w t . ~ \% )}$ & $\mathbf{C u F e S}_{\mathbf{2}}$ & $\mathbf{F e}_{\mathbf{1 - \mathbf { x }}} \mathbf{S}$ & $\mathbf{C u F e S}_{\mathbf{2}}$ & $\mathbf{F e}_{\mathbf{1 - \mathbf { x }}} \mathbf{S}$ \\
\hline Concentrate & $53.00 \pm 0.68$ & $85.73 \pm 0.37$ & $20.20 \pm 0.33$ & $80.97 \pm 0.40$ & $19.03 \pm 0.40$ \\
Tailing & $47.00 \pm 0.68$ & $14.27 \pm 0.37$ & $79.80 \pm 0.33$ & $15.20 \pm 0.37$ & $84.80 \pm 0.37$ \\
Flotation feed & 100 & 100 & 100 & 50 & 50 \\
\hline
\end{tabular}

To summarize, all of the flotation experimental results indicate that the PGA has a superior selective depression effect on pyrrhotite in the selective flotation of chalcopyrite with xanthate as the collector. Thus, the optimal usage of PGA could replace the most toxic inorganic depressants in copper ore industry, and could reduce the environmental impacts of processing.

\subsection{Zeta Potential}

The essential reaction behavior of PGA with chalcopyrite and pyrite was investigated through zeta potential measurements. As can be seen in Figure 6, untreated pyrrhotite particles represented a highly positive zeta potential charge in a wide $\mathrm{pH}$ range of $3-7$, with an isoelectric point at $\mathrm{pH} 7.4$. Whereas, untreated chalcopyrite particles indicated comparatively less positive charge, with an isoelectric point less than $\mathrm{pH}$ 4. The highly positive charge and isoelectric point at higher $\mathrm{pH}$ has been reported to indicate the presence of oxidation species on the pyrrhotite surface $[35,36]$. The addition of SBX significantly decreased the zeta potentials of chalcopyrite and pyrrhotite simultaneously, indicating that the xanthate anions were strongly absorbed on the pyrrhotite and chalcopyrite surfaces before the treatment with PGA. These results validate the mineral flotation tests indicating that both minerals were highly floatable with SBX. Moreover, an important difference in the zeta potentials of chalcopyrite and pyrrhotite particles in the presence of PGA clearly shows that PGA behaved differently with the two minerals. This important difference certainly caused the different flotation behaviors of chalcopyrite and pyrrhotite in the single and binary mineral selective flotation experiments.
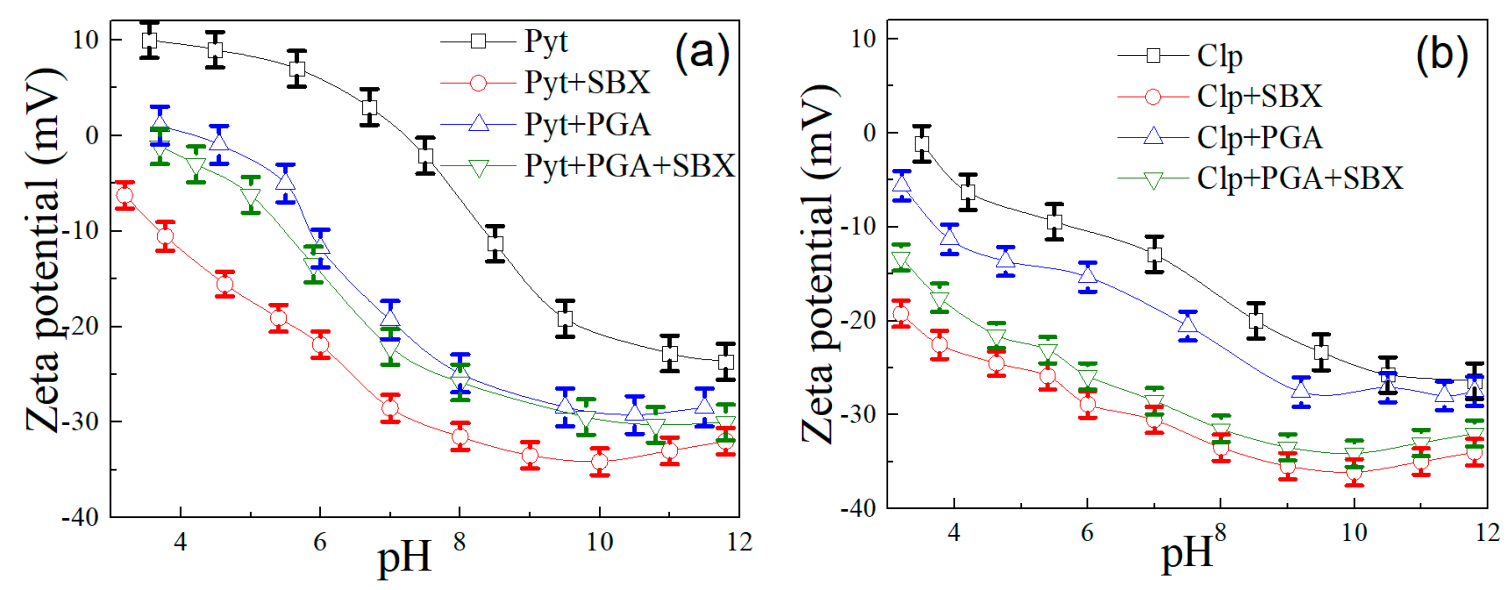

Figure 6. Zeta potential results of (a) pyrrhotite (Pyt) and (b) chalcopyrite (Clp) at $50 \mathrm{mg} / \mathrm{L} \mathrm{PGA}$ and $20 \mathrm{mg} / \mathrm{L}$ SBX. 
As shown in Figure 6, PGA decreased the zeta potentials of pyrrhotite particles more strongly than that of the chalcopyrite, indicating that, the surface of pyrrhotite was more susceptible than chalcopyrite to PGA reaction. In the presence of PGA, the zeta potentials of pyrrhotite particles were decreased to approximately $10 \mathrm{mV}$, especially in the $\mathrm{pH}$ range $5-10$, compared to a decrease of approximately $4 \mathrm{mV}$ for the chalcopyrite.

As described previously, PGA is a naturally occurring polymer that is chemically composed of glutamic acids. It contains two carboxyl groups $(-\mathrm{COOH})$ and one amino group $\left(-\mathrm{NH}_{2}\right)$ in its molecular structure, with a chemical formula of $\mathrm{HOOC}-\mathrm{CH}\left(\mathrm{NH}_{2}\right)-\left(\mathrm{CH}_{2}\right)_{2}-\mathrm{COOH}$. PGA is an anionic biopolymer; however, its charge varies depending on $\mathrm{pH}$ of the solution [37]. In highly acidic solutions $(\mathrm{pH}<2)$, the amino group gains a proton and the molecule becomes positively charged, HOOC- $-\mathrm{CH}\left(\mathrm{NH}^{+3}\right)-\left(\mathrm{CH}_{2}\right)_{2}-\mathrm{COOH}$. In the $\mathrm{pH}$ range of $2-4$, the carboxylic acid closer to the amine loses a proton and the molecule becomes a neutral zwitterion, $-\mathrm{OOC}-\mathrm{CH}\left(\mathrm{NH}^{+3}\right)-\left(\mathrm{CH}_{2}\right)_{2}-\mathrm{COOH}$. In neutral solutions ( $\mathrm{pH}$ range 7-7.5), the other carboxylic acid group loses a proton to form a conjugate base. Under these conditions, the molecule formed is known as singly-negative anion glutamate $-\mathrm{OOC}-\mathrm{CH}\left(\mathrm{NH}^{+3}\right)-\left(\mathrm{CH}_{2}\right)_{2}-\mathrm{COO}-[38]$. Whereas, in highly alkaline environments $(\mathrm{pH}>8)$, the prevalent species is the doubly-negative anion -OOC-CH( $\left(\mathrm{NH}_{2}\right)-\left(\mathrm{CH}_{2}\right)_{2}-\mathrm{COO}-$.

Based on these observations, it could be hypothesized that PGA adsorbed mainly through its negatively charged functional groups, and the stronger decrease in zeta potential of pyrrhotite may be attributed to the adsorption of PGA anions on the pyrrhotite surface, as it was comparatively more positive than chalcopyrite. More interestingly, the presence of the collector (SBX) greatly reduced the zeta potentials of PGA-adsorbed chalcopyrite by more than $10 \mathrm{mV}$, suggesting that the adsorption of PGA was much weaker on the surface of chalcopyrite. In contrast, the zeta potential of PGA-adsorbed pyrrhotite was slightly reduced after the addition of SBX; a minor decrease of approximately $2.5 \mathrm{mV}$ could only be noted at a low $\mathrm{pH}$ range of 4-7. However, no significant shift in the zeta potential of PGA-adsorbed pyrrhotite was noted after increasing the solution $\mathrm{pH}$ beyond 7 , indicating that the pre-adsorption of PGA strongly inhibited the adsorption of collector onto the pyrrhotite surface.

To summarize, PGA reacted differently with the two minerals and it had a stronger affinity towards the surface of pyrrhotite than chalcopyrite. The prior addition of PGA formed a passive negatively charged layer on the pyrrhotite surface, which inhibited the adsorption of collector and thus caused the depression of pyrrhotite. The significant adsorption of collector onto the PGA-adsorbed chalcopyrite surface indicates that PGA has a weaker interaction towards the chalcopyrite surface.

\subsection{Reagent Adsorption}

Zeta potential results indicated that PGA behaved differently with the two minerals and it had a stronger affinity towards the surface of pyrrhotite than chalcopyrite. To verify the zeta potential results, the amounts of PGA adsorbed onto the chalcopyrite and pyrrhotite surfaces were determined at different PGA doses. As shown in Figure 7, by increasing the reagent doses, the adsorption of PGA was increased linearly and simultaneously on the surface of both minerals. As can be seen, at the same doses of PGA, the adsorption density of PGA onto the pyrrhotite surface was much greater compared with the chalcopyrite. Hence, the reagent adsorption results confirmed the zeta potential measurements and showed that the PGA densely adsorbed onto the pyrrhotite surface. Thus, the significant decrease in zeta potentials of pyrrhotite compared with the chalcopyrite could be attributed to the higher adsorption density of PGA on the pyrrhotite surface. 


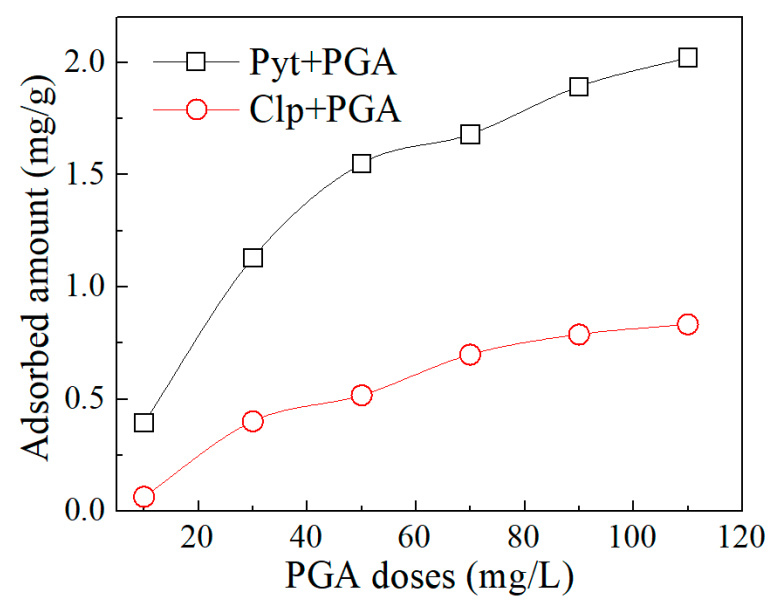

Figure 7. PGA adsorption on pyrrhotite (Pyt) and chalcopyrite (Clp) at different concentrations of PGA at $\mathrm{pH} 8$.

\subsection{Infrared Spectroscopy}

Infrared spectroscopy was further performed to explore the reaction mechanism of PGA on the mineral surfaces. Figure 8 demonstrates the infrared spectra of mineral particles in the presence of different flotation reagents. The infrared spectra of untreated particles of chalcopyrite and pyrrhotite were in good agreement with the previous reported studies. In the pyrrhotite spectrum, the presence of peaks around $1085.04,1026.88$, and $792.52 \mathrm{~cm}^{-1}$ corresponding to $\mathrm{FeO}, \mathrm{Fe}(\mathrm{OH})_{2}$, and $\mathrm{Fe}\left(\mathrm{SO}_{4}\right)_{3}$ indicate the existence of oxidation species on pyrrhotite surface [36,39]. Moreover, the spectrum of pyrrhotite after the treatment with SBX indicated the possible peaks of xanthate-iron complexes $\left(1079.91 \mathrm{~cm}^{-1}\right)$, dixanthogen $\left(1269.03 \mathrm{~cm}^{-1}\right)$, and $\mathrm{CH}_{2}$ groups $\left(2975.13 \mathrm{~cm}^{-1}\right)$ on the pyrrhotite surface. Similarly, in the spectrum of chalcopyrite after the treatment with SBX, the peaks around 1079.73, 1269.00, and $2930.81 \mathrm{~cm}^{-1}$ correspond to xanthate-copper complexes, dixanthogen, and $\mathrm{CH}_{2}$ groups on chalcopyrite surface, respectively. These results indicate that the collector was strongly absorbed on the pyrrhotite and chalcopyrite surface before the treatment with PGA.

Figure 8a displays that the reaction of PGA produced the characteristic adsorption peaks of -COOH groups (1558.76 and $\left.1403.35 \mathrm{~cm}^{-1}\right), \mathrm{C}-\mathrm{N}$ groups $\left(1290.32 \mathrm{~cm}^{-1}\right),-\mathrm{CH}_{2}$ groups $\left(2950.83 \mathrm{~cm}^{-1}\right)$, and $-\mathrm{CONH}$ groups $\left(3441.50 \mathrm{~cm}^{-1}\right)$ on the pyrrhotite surface. In addition, the surface oxidation peaks on pyrrhotite were reduced in intensity and shifted to lower values at 1084.13, 1025.21, and $791.06 \mathrm{~cm}^{-1}$ after reacting with PGA. The disappearance or decrease of surface oxidation peaks indicated that the addition of PGA formed a passive layer on the pyrrhotite surface. The significant shifts in surface oxidation peaks and PGA adsorption peaks (Figure 2) provided evidence in support of a chemisorption mechanism between pyrrhotite and PGA. As can be seen, the adsorption peaks of xanthate and/or dixanthogen did not appear after the subsequent addition of the collector (SBX), which further supported the strong chemical reaction of PGA onto the pyrrhotite surface. Thus, these results indicate that the prior addition of PGA blocked the electrochemical activity of the collector onto the pyrrhotite surface.

Figure $8 \mathrm{~b}$ illustrates the infrared spectra of chalcopyrite under the same experimental conditions. It is apparent that, compared with pyrrhotite, the PGA reacted weakly with the chalcopyrite surface. The weaker characteristic adsorption peaks of $-\mathrm{CH}_{2}$ groups $\left(2852.30\right.$ and $\left.2930.81 \mathrm{~cm}^{-1}\right)$ suggest that PGA adsorbed onto the chalcopyrite surface only through hydrogen bonding. Moreover, the xanthate adsorption peaks $\left(1079.73 \mathrm{~cm}^{-1}\right.$, copper-xanthate compounds) and dixanthogen peaks $\left(1269.00 \mathrm{~cm}^{-1}\right)$ appeared on the surface of PGA-treated chalcopyrite, supporting further the weaker affinity of PGA for the chalcopyrite. These results therefore infer that the collector was effectively adsorbed and oxidized to the dixanthogen on the chalcopyrite surface, even in the presence of PGA. 
Polyglutamic acid is one of the categories of polysaccharide-based polymers whose adsorption behavior depends essentially on the extent of hydroxyl metal species present on the mineral surfaces [40-42]. Zeta potential measurements and infrared spectral analysis indicated the presence of surface oxidation species on the pyrrhotite surface. Therefore, the much greater affinity of PGA towards pyrrhotite compared with chalcopyrite can be attributed to the presence surface oxidation species on pyrrhotite surface; PGA formed chemical coordination with $\mathrm{FeO}, \mathrm{Fe}(\mathrm{OH})_{2}$, and $\mathrm{Fe}\left(\mathrm{SO}_{4}\right)_{3}$ species on the pyrrhotite surface. Similar adsorption mechanisms have also been reported for other organic depressants on the oxidized pyrite surface $[43,44]$.
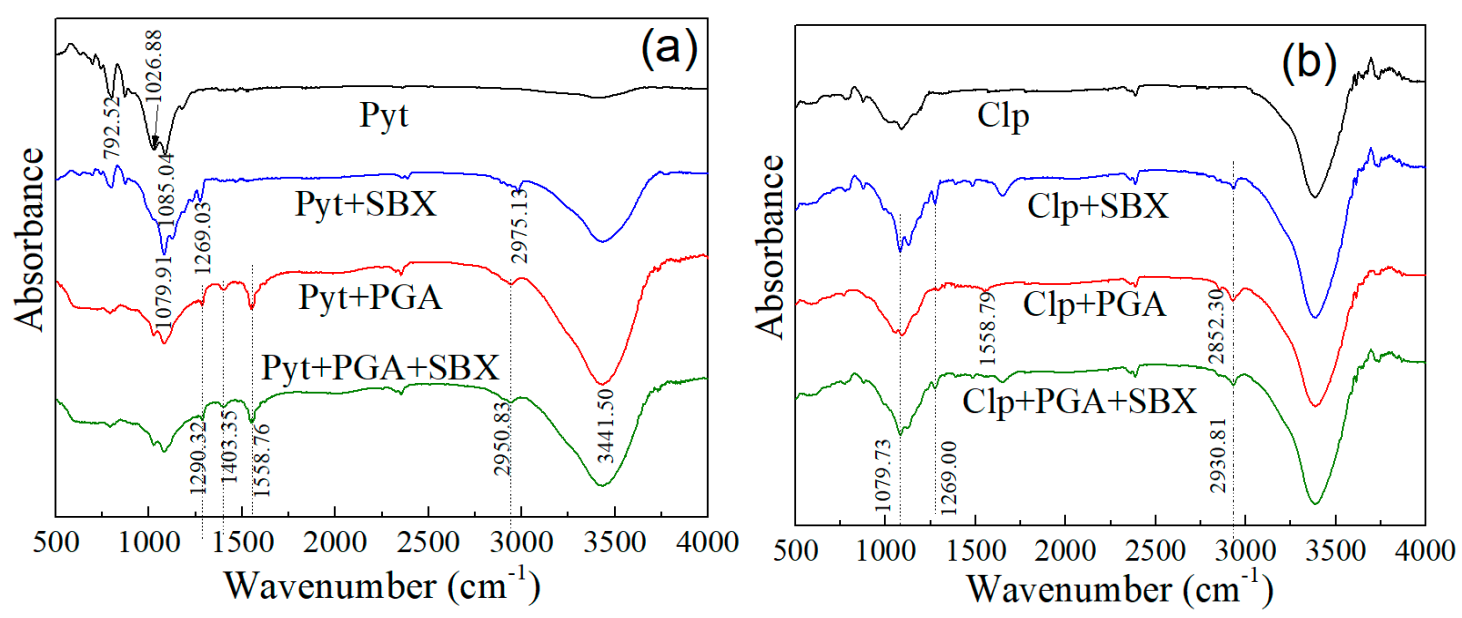

Figure 8. Infrared spectral results of (a) pyrrhotite (Pyt) and (b) chalcopyrite (Clp) at $50 \mathrm{mg} / \mathrm{L} \mathrm{PGA,}$ $20 \mathrm{mg} / \mathrm{L} \mathrm{SBX}$, and $\mathrm{pH} 8$.

\subsection{X-ray Photoelectron Spectroscopy}

X-ray photoelectron spectroscopic (XPS) measurements are the best tools to determine the chemical surface species on mineral surfaces for reagent adsorption. The XPS full survey spectra of mineral particles before and after the reaction with PGA are shown in Figure 9. The elemental concentration and the changes in the binding energies of elements after the reaction with PGA are shown in Tables 3 and 4 , respectively.
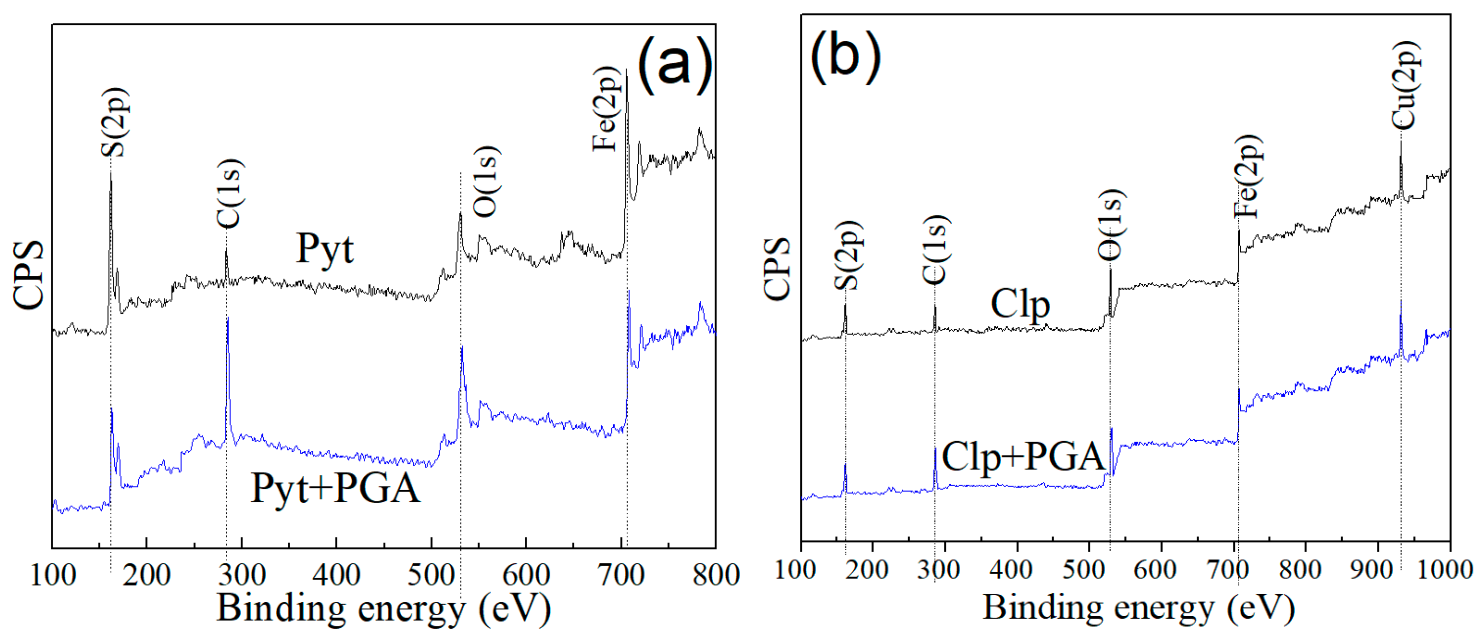

Figure 9. XPS spectral results of (a) pyrrhotite (Pyt) and (b) chalcopyrite (Clp) before and after the reaction with $50 \mathrm{mg} / \mathrm{L}$ PGA at $\mathrm{pH} 8$. 
Table 3. Elemental concentration of important species in the absence and presence of $50 \mathrm{mg} / \mathrm{L} \mathrm{PGA}$ at $\mathrm{pH} 8$.

\begin{tabular}{cccccc}
\hline \multirow{2}{*}{ Sample } & \multicolumn{5}{c}{ Elemental Concentration (\%) } \\
\cline { 2 - 6 } & $\mathbf{C u}$ & Fe & S & O & C \\
\hline Pyrrhotite & - & 32.93 & 41.96 & 21.89 & 3.21 \\
Pyrrhotite with PGA & - & 19.31 & 27.01 & 34.11 & 19.51 \\
Chalcopyrite & 27.03 & 16.31 & 31.45 & 21.63 & 3.51 \\
Chalcopyrite with PGA & 23.39 & 14.93 & 29.38 & 23.37 & 8.89 \\
\hline
\end{tabular}

Table 4. Binding energies of important species in the absence and presence of $50 \mathrm{mg} / \mathrm{L}$ PGA at pH 8.

\begin{tabular}{ccccccccccc}
\hline \multirow{2}{*}{ Sample } & \multicolumn{4}{c}{ Binding Energy (eV) } & \multicolumn{5}{c}{ Chemical Shift (eV) } \\
\cline { 2 - 10 } & $\mathbf{C u}(\mathbf{2 p})$ & $\mathbf{F e}(\mathbf{2 p})$ & $\mathbf{S ( 2 p )}$ & $\mathbf{O}(\mathbf{1 s})$ & $\mathbf{C}(\mathbf{1 s})$ & $\mathbf{C u}(\mathbf{2 p})$ & $\mathbf{F e}(\mathbf{2 p})$ & $\mathbf{S}(\mathbf{2 p})$ & $\mathbf{O}(\mathbf{1 s})$ & $\mathbf{C}(\mathbf{1 s})$ \\
\hline Pyrrhotite & - & 707.45 & 161.47 & 530.33 & 284.33 & - & - & - & - & - \\
Pyrrhotite with PGA & - & 708.01 & 162.00 & 531.03 & 284.93 & - & 0.56 & 0.53 & 0.70 & 0.60 \\
$\begin{array}{c}\text { Chalcopyrite } \\
\text { Chalcopyrite with } \\
\text { PGA }\end{array}$ & 931.81 & 707.51 & 161.49 & 529.91 & 284.79 & - & & - & - & - \\
\hline
\end{tabular}

The significant broadness and higher intensities of $S(2 p)$ and $O(1 s)$ peaks before the reaction with PGA provided the evidence of surface oxidation species on the pyrrhotite surface. Pyrrhotite is a very sensitive mineral that rapidly oxidized during the sample preparation procedures in open atmosphere, and thus its surface was covered with ferric hydroxide and or sulfate species. The significant changes in the surface of the pyrrhotite compared with chalcopyrite confirmed the conclusions drawn from the above-mentioned measurements-that PGA had a superior affinity towards pyrrhotite compared to chalcopyrite. As is shown, the intensities of $C$ and $O$ peaks were significantly increased, and those of Fe and $\mathrm{S}$ peaks were decreased after the adsorption of PGA onto the mineral surfaces. However, the percentage increase in the atomic concentration of oxygen and carbon and the percentage decrease in the atomic concentration of iron and sulfur on pyrrhotite surface were more apparent compared with those on the chalcopyrite surface (Table 3), clearly indicating that the surface of pyrrhotite adsorbed a much greater amount of PGA than that of the chalcopyrite.

Moreover, the addition of PGA significantly shifted the binding energies of the most important species ( $\mathrm{Fe}, \mathrm{S}, \mathrm{C}$, and $\mathrm{O}$ ) on the pyrrhotite surface. As the shifts in the binding energies of $\mathrm{Fe}(2 \mathrm{p}), \mathrm{S}(2 \mathrm{p})$, $\mathrm{C}(1 \mathrm{~s})$, and $\mathrm{O}(1 \mathrm{~s})$ species were more than $0.1 \mathrm{eV}$ (Table 4), it suggests a strong chemical reaction of PGA onto the pyrrhotite surface. Under the sample experimental conditions, the binding energy shifts in these species on the chalcopyrite surface were very low (less than $0.1 \mathrm{eV}$ ), representing a much weaker reaction of PGA onto the chalcopyrite-most likely physical adsorption. As described previously, the enhanced affinity of PGA towards pyrrhotite compared with chalcopyrite is attributed to the presence of hydroxyl oxidation species on pyrrhotite surface.

Polyglutamic acid contains very reactive functional groups such as $-\mathrm{COOH}$ and $-\mathrm{OH}$ on its molecular structure, which played an important role for the adsorption of PGA onto the mineral surfaces. To acquire this information, the high-resolution XPS spectra of $\mathrm{O}(1 \mathrm{~s})$ species from the surfaces of both minerals in the presence of PGA were collected and best-fitted into the possible existing peaks as shown in shown Figure 10. In the pyrrhotite spectrum before the reaction with PGA, the peaks with the binding energies of $529.91,530.01$, and $532.00 \mathrm{eV}$ corresponded to $\mathrm{O}^{2-},-\mathrm{OH}$, and $\mathrm{SO}^{-}{ }_{4}$ species, respectively [45]. The presence of such species indicated that the pyrrhotite surface contained surface oxidation species.

As can be seen in Figure 10a, the reaction of PGA increased the intensities and broadened the peaks of $\mathrm{O}^{2-},-\mathrm{OH}$, and $\mathrm{SO}^{-}$species on the pyrrhotite surface. The more pronounced peak with a binding energy of about $532.353 \mathrm{eV}$ corresponded to the double oxygen atoms of the deprotonated carboxylic groups (carboxylate groups) [46]. This implies that the PGA adsorbed mainly through its oxygen atoms. Figure 10b portrays the high-resolution XPS spectra of $\mathrm{O}(1 \mathrm{~s})$ species from the chalcopyrite 
surface under the same experimental conditions. As is shown, the chalcopyrite surface did not show the peaks of $-\mathrm{OH}$ and $\mathrm{SO}_{4}^{-}$species; the peak around $529.93 \mathrm{eV}$ may be assigned to lattice oxygen. Little to no changes in the binding energies of the lattice oxygen provided clear evidence that there was a very limited effect of PGA on the chalcopyrite surface.
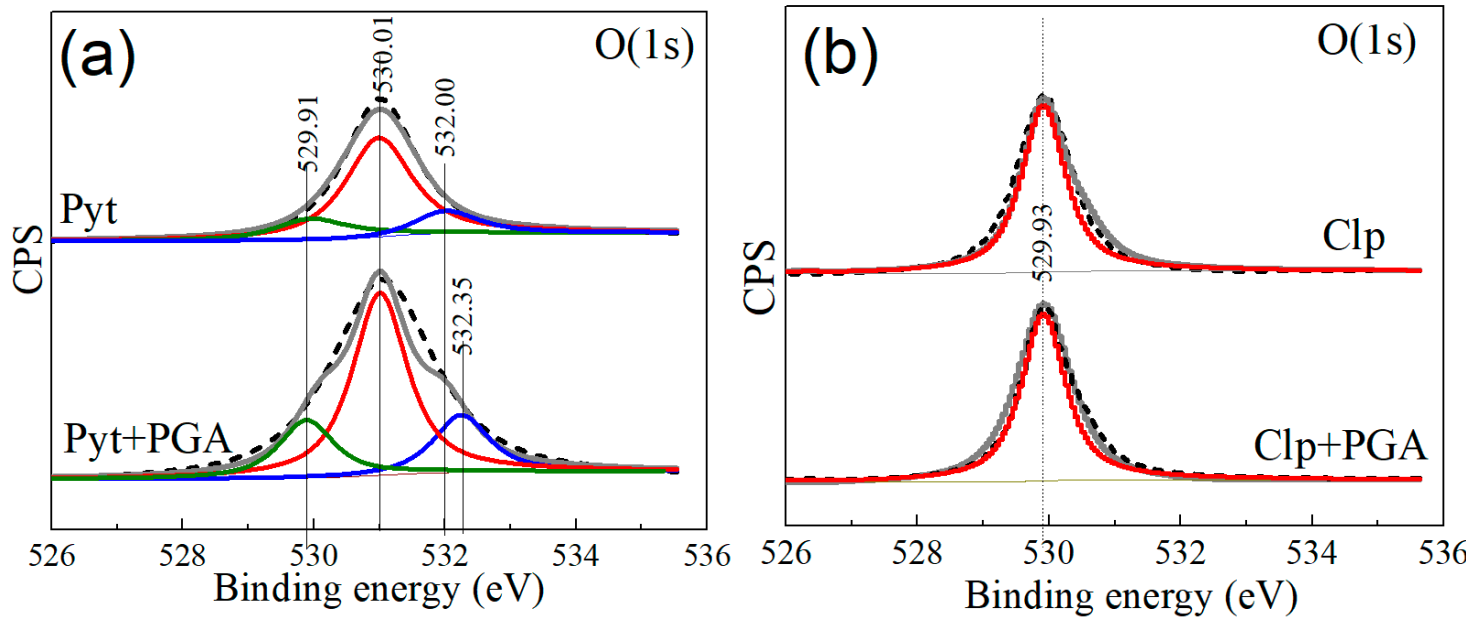

Figure 10. High-resolution XPS spectra of $\mathrm{O}(1 \mathrm{~s})$ species from surfaces of (a) pyrrhotite (Pyt) and (b) chalcopyrite (Clp) before and after the reaction with $50 \mathrm{mg} / \mathrm{L} \mathrm{PGA}$ at $\mathrm{pH} 8$.

\subsection{Adsorption Model and Depression Mechanism of PGA on Pyrrhotite}

Flotation results indicated that the addition of PGA depressed the flotation of pyrrhotite much more strongly than chalcopyrite. Surface measurement techniques including zeta potential, reagent adsorption, IR spectral, and XPS spectral analyses showed that PGA considerably adsorbed and modified the surface properties of pyrrhotite and enhanced its hydrophilic character. The IR and XPS spectral analyses suggested that PGA formed chemical bonds with the hydroxyl oxidation species on the pyrrhotite surface. Overall, the prior addition of PGA significantly reduced the adsorption of the collector and its oxidation to dixanthogen onto the pyrrhotite surface, and thus depressed the flotation of pyrrhotite. Based on these observations, an adsorption model and depression mechanism of PGA on the pyrrhotite in the presence of collector (xanthate) is proposed. Figure 11 shows an illustrative scheme for the systematic inhibition behavior of PGA on the pyrrhotite surface.

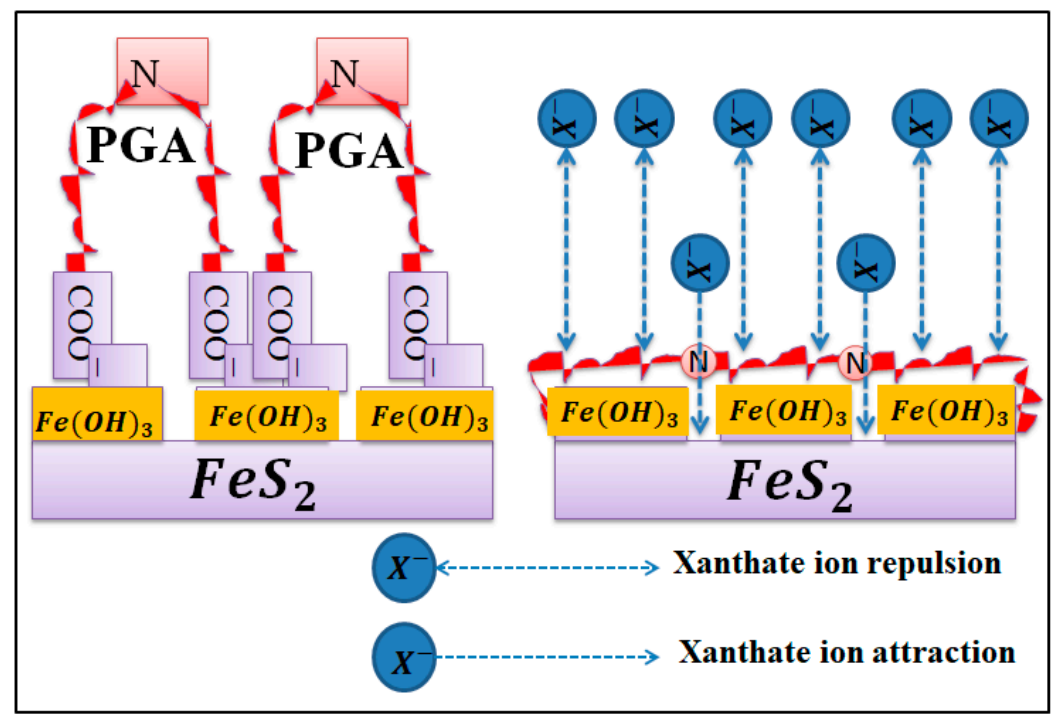

Figure 11. Schematic illustration of the adsorption model and depression mechanism of PGA on pyrrhotite. 


\section{Conclusions}

The depression and adsorption mechanism of a novel reagent, polyglutamic acid (PGA), on chalcopyrite and pyrrhotite flotation separation was successfully investigated in this study. The main findings can be summarized as follows:

(1) Single-mineral flotation results revealed that the addition of PGA inhibited the flotation of pyrrhotite more strongly than that of the chalcopyrite. The prior addition of PGA achieved an improved selective separation of chalcopyrite from pyrrhotite with sodium butyl xanthate as the collector, at which the flotation concentrate with an improved chalcopyrite grade and recovery of over $80 \%$ was received.

(2) All of the surface analysis techniques, including zeta potential analysis, reagent adsorption analysis, IR spectral measurements, and XPS spectral measurements, revealed that the PGA behaved differently with the two minerals, and the pyrrhotite surface showed much greater affinity towards PGA.

(3) IR spectral and XPS spectral analyses provided evidence in support of a chemical reaction between the PGA and pyrrhotite surface; PGA formed chemical bonds with the hydroxyl oxidation species on the pyrrhotite surface.

(4) The prior addition of PGA blocked the electrochemical activity between the collector and pyrrhotite surface, and thus depressed the flotation of pyrrhotite. In contrast, the collector significantly adsorbed and oxidized to the dixanthogen on the chalcopyrite surface, which improved its flotation even in the presence of PGA.

The findings of this study suggest that PGA has a superior depressive selectivity towards the iron-bearing sulfide gangues in $\mathrm{Cu}$-Fe flotation systems. The optimum usage of PGA could replace the most toxic inorganic depressants in the copper ore industry and could reduce the environmental impacts of processing.

Author Contributions: Conceptualization, Y.H. and W.S.; experimental methodology and writing—original draft preparation, S.A.K.; writing - review and editing, Z.G. and X.M.

Funding: This research was supported by the Natural Science Foundation of China (No. 51634009); the Innovation Driven Plan of Central South University (No. 2015CX005); the National 111 Project (No. B14034); the Collaborative Innovation Centre for Clean and Efficient Utilization of Strategic Metal Mineral Resources, the Key Laboratory of Hunan Province for Clean and Efficient Utilization of Strategic Calcium-containing Mineral Resources (No. 2018TP1002), and the Fundamental Research Funds for the Central Universities of Central South University (No. 2018zzts227).

Conflicts of Interest: The authors declare no conflicts of interest.

\section{References}

1. Agar, G.E. Flotation of chalcopyrite, pentlandite, pyrrhotite ores. Int. J. Miner. Process. 1991, 33, 1-19. [CrossRef]

2. Cheng, X.; Iwasaki, I. Effect of chalcopyrite and pyrrhotite interaction on flotation separation. Min. Met. Explor. 1992, 9, 73-79. [CrossRef]

3. Allison, S.; O'Connor, C. An investigation into the flotation behaviour of pyrrhotite. Int. J. Miner. Process. 2011, 98, 202-207. [CrossRef]

4. Chimbganda, T.; Becker, M.; Broadhurst, J.; Harrison, S.; Franzidis, J.P.; Broadhurst, J. A comparison of pyrrhotite rejection and passivation in two nickel ores. Miner. Eng. 2013, 46, 38-44. [CrossRef]

5. Moslemi, H.; Shamsi, P.; Habashi, F. Pyrite and pyrrhotite open circuit potentials study: Effects on flotation. Miner. Eng. 2011, 24, 1038-1045. [CrossRef]

6. Bozkurt, V.; $\mathrm{Xu}, \mathrm{Z}$.; Finch, J. Pentlandite/pyrrhotite interaction and xanthate adsorption. Int. J. Miner. Process. 1998, 52, 203-214. [CrossRef]

7. Becker, M.; De Villiers, J.; Bradshaw, D. The flotation of magnetic and non-magnetic pyrrhotite from selected nickel ore deposits. Miner. Eng. 2010, 23, 1045-1052. [CrossRef]

8. Dong, J.; Xu, M. Method for improving selectivity and recovery in the flotation of nickel sulphide ores that contain pyrrhotite by exploiting the synergy of multiple depressants. U.S. Patent 20140305848A1, 12 July 2016. 
9. Khoso, S.A.; Abro, M.I.; Agheem, M.H. Mineralogical Study of Zard Koh and Kulli Koh Iron Ore Deposits of Pakistan. Mehran Univ. Res. J. Eng. Technol. 2017, 36, 1017-1024. [CrossRef]

10. Kelebek, S.; Wells, P.; Fekete, S. Differential flotation of chalcopyrite, pentlandite and pyrrhotite in Ni-Cu sulphide ores. Can. Metall. Q. 1996, 35, 329-336.

11. Multani, R.S.; Williams, H.; Johnson, B.; Li, R.; Waters, K.E. The effect of superstructure on the zeta potential, xanthate adsorption, and flotation response of pyrrhotite. Colloids Surf. A: Physicochem. Eng. Asp. 2018, 551, 108-116. [CrossRef]

12. Zhao, C.-H.; Wu, B.Z.; Chen, J.H. Electronic structure and flotation behavior of monoclinic and hexagonal pyrrhotite. J. Cent. South Univ. 2015, 22, 466-471. [CrossRef]

13. Qi, C.; Liu, J.; Malainey, J.; Kormos, L.J.; Coffin, J.; Deredin, C.; Liu, Q.; Fragomeni, D. The role of Cu ion activation and surface oxidation for polymorphic pyrrhotite flotation performance in Strathcona Mill. Miner. Eng. 2019, 134, 87-96. [CrossRef]

14. Prestidge, C.A.; Ralston, J.; Smart, R.S. The competitive adsorption of cyanide and ethyl xanthate on pyrite and pyrrhotite surfaces. Int. J. Miner. Process. 1993, 38, 205-233. [CrossRef]

15. Da Silva, G.; Waters, K. The effects of microwave irradiation on the floatability of chalcopyrite, pentlandite and pyrrhotite. Adv. Powder Technol. 2018, 29, 3049-3061. [CrossRef]

16. Tukel, C.; Kelebek, S. Modulation of xanthate action by sulphite ions in pyrrhotite deactivation/depression. Int. J. Miner. Process. 2010, 95, 47-52. [CrossRef]

17. Zhou, J.; Lu, Y.; Mao, G. Separation of Oxidized Pyrrhotite from Fine Fraction Serpentine. Minerals 2018, 8, 472. [CrossRef]

18. Liu, J.; Yuan, S.; Han, Y.; Li, Y. The effects of various activators on flotation performance of lime-depressed pyrrhotite. Can. Metall. Q. 2018, 58,1-8.

19. Miller, J.; Li, J.; Davidtz, J.; Vos, F.; Vos, C. A review of pyrrhotite flotation chemistry in the processing of PGM ores. Miner. Eng. 2005, 18, 855-865. [CrossRef]

20. Arvidson, B.; Klemetti, M.; Knuutinen, T.; Kuusisto, M.; Man, Y.; Hughes-Narborough, C. Flotation of pyrrhotite to produce magnetite concentrates with a sulphur level below 0.05\% w/w. Miner. Eng. 2013, 50, 4-12. [CrossRef]

21. Zhao, C.; Huang, D.; Chen, J.; Li, Y.; Chen, Y.; Li, W. The interaction of cyanide with pyrite, marcasite and pyrrhotite. Miner. Eng. 2016, 95, 131-137. [CrossRef]

22. October, L.; Corin, K.; Schreithofer, N.; Manono, M.; Wiese, J. Water quality effects on bubble-particle attachment of pyrrhotite. Miner. Eng. 2019, 131, 230-236. [CrossRef]

23. Multani, R.S.; Waters, K.E. Flotation recovery-by-size comparison of pyrrhotite superstructures with and without depressants. Miner. Eng. 2019, 130, 92-100. [CrossRef]

24. Sun, W.; Liu, R.-Q.; Cao, X.-F.; Hu, Y.-H. Flotation separation of marmatite from pyrrhotite using DMPS as depressant. Trans. Nonferrous Met. Soc. China 2006, 16, 671-675. [CrossRef]

25. Chen, X.; Guohua, G.; Lijuan, L.; Zhixiang, C. Effect of food-grade guar gum on flotation separation of chalcopyrite and monoclinic pyrrhotite in low-alkali systems. Physicochem. Probl. Miner. Process. 2019, 55, 437-447.

26. Yoon, R.H.; Basilio, C.; Marticorena, M.; Kerr, A.; Stratton-Crawley, R. A study of the pyrrhotite depression mechanism by diethylenetriamine. Miner. Eng. 1995, 8, 807-816. [CrossRef]

27. Kelebek, S.; Tukel, C. The effect of sodium metabisulfite and triethylenetetramine system on pentlandite-pyrrhotite separation. Int. J. Miner. Process. 1999, 57, 135-152. [CrossRef]

28. Gu, G.; Zhao, K.; Qiu, G.; Hu, Y.; Sun, X. Effects of Leptospirillum ferriphilum and Acidithiobacillus caldus on surface properties of pyrrhotite. Hydrometally 2009, 100, 72-75. [CrossRef]

29. Mu, Y.; Peng, Y.; Lauten, R.A. The depression of pyrite in selective flotation by different reagent systems-A Literature review. Miner. Eng. 2016, 96, 143-156. [CrossRef]

30. Mu, Y.; Peng, Y.; Lauten, R.A. The depression of copper-activated pyrite in flotation by biopolymers with different compositions. Miner. Eng. 2016, 96, 113-122. [CrossRef]

31. Khoso, S.A.; Hu, Y.; Lyu, F.; Liu, R.; Sun, W. Selective separation of chalcopyrite from pyrite with a novel non-hazardous biodegradable depressant. J. Clean. Prod. 2019, 232, 888-897. [CrossRef]

32. Khoso, S.A.; Hu, Y.; Liu, R.; Tian, M.; Sun, W.; Gao, Y.; Han, H.; Gao, Z. Selective depression of pyrite with a novel functionally modified biopolymer in a Cu-Fe flotation system. Miner. Eng. 2019, 135, 55-63. [CrossRef] 
33. Luo, Z.; Guo, Y.; Liu, J.; Qiu, H.; Zhao, M.; Zou, W.; Li, S. Microbial synthesis of poly- $\gamma$-glutamic acid: current progress, challenges, and future perspectives. Biotechnol. Biofuels 2016, 9, 207. [CrossRef] [PubMed]

34. Fuerstenau, M.C.; Jameson, G.J.; Yoon, R.H. Froth Flotation: A Century of Innovation; Society for Mining, Metallurgy, and Exploration: Englewood, CO, USA, 2007.

35. Valdivieso, A.L.; Cervantes, T.C.; Song, S.; Cabrera, A.R.; Laskowski, J. Dextrin as a non-toxic depressant for pyrite in flotation with xanthates as collector. Miner. Eng. 2004, 17, 1001-1006. [CrossRef]

36. Fornasiero, D.; Ralston, J. Iron hydroxide complexes and their influence on the interaction between ethyl xanthate and pyrite. J. Colloid Interface Sci. 1992, 151, 225-235. [CrossRef]

37. Neuberger, A. Dissociation constants and structures of glutamic acid and its esters. Biochem. J. 1936, 30, 2085-2094. [CrossRef] [PubMed]

38. Lehmann, M.S.; Koetzle, T.F.; Hamilton, W.C. Precision neutron diffraction structure determination of protein and nucleic acid components. VIII: The crystal and molecular structure of the $\beta$-form of the amino acid l-glutamic acid. J. Cryst. Mol. Struct. 1972, 2, 225-233. [CrossRef]

39. Clarke, P.; Fornasiero, D.; Ralston, J.; Smart, R. A study of the removal of oxidation products from sulfide mineral surfaces. Miner. Eng. 1995, 8, 1347-1357. [CrossRef]

40. Shrimali, K.; Atluri, V.; Wang, X.; Miller, J.D. Adsorption of corn starch molecules at hydrophobic mineral surfaces. Colloids Surfaces A: Physicochem. Eng. Asp. 2018, 546, 194-202. [CrossRef]

41. Liu, Q.; Laskowski, J. The interactions between dextrin and metal hydroxides in aqueous solutions. J. Colloid Interface Sci. 1989, 130, 101-111. [CrossRef]

42. Khosla, N.K.; Bhagat, R.P.; Gandhi, K.S.; Biswas, A.K. Calorimetric and other interaction studies on mineral—starch adsorption systems. Colloids Surf. 1984, 8, 321-336. [CrossRef]

43. López-Valdivieso, A.; Sánchez-López, A.A.; Padilla-Ortega, E.; Robledo-Cabrera, A.; Galvez, E.; Cisternas, L. Pyrite depression by dextrin in flotation with xanthates. Adsorption and floatability studies. Physicochem. Probl. Miner. Process 2018, 54, 1159-1171.

44. Lopez Valdivieso, A.; Sánchez López, A.; Song, S.; García Martínez, H.; Licón Almada, S. Dextrin as a regulator for the selective flotation of chalcopyrite, galena and pyrite. Can. Metall. Q. 2007, 46, 301-309. [CrossRef]

45. Mikhlin, Y.; Varnek, V.; Asanov, I.; Tomashevich, Y.; Okotrub, A.; Livshits, A.; Selyutin, G.; Pashkov, G. Reactivity of pyrrhotite (Fe9S10) surfaces: Spectroscopic studies. Phys. Chem. Chem. Phys. 2000, 2, 4393-4398. [CrossRef]

46. Moreira, G.F.; Peçanha, E.R.; Monte, M.B.M.; Leal Filho, L.S.; Stavale, F. XPS study on the mechanism of starch-hematite surface chemical complexation. Miner. Eng. 2017, 110, 96-103. [CrossRef] 